\title{
Frequency of recurrent urinary tract infection in patients with pelvic organ prolapse
}

This article was published in the following Dove Press journal:

Research and Reports in Urology

28 January 2015

Number of times this article has been viewed

\author{
Emrah Töz' \\ Sefa Kurt ${ }^{2}$ \\ Çağdaș Sahin' \\ Mehmet Tunç Canda ${ }^{3}$ \\ 'Department of Obstetrics and \\ Gynecology, Tepecik Training and \\ Research Hospital, Izmir, Turkey; \\ ${ }^{2}$ Department of Obstetrics and \\ Gynecology, Izmir Dokuz Eylül \\ University, Izmir, Turkey; ${ }^{3}$ Department \\ of Obstetrics and Gynecology, Kent \\ Hospital, Izmir, Turkey
}

Purpose: The aim of the study was to investigate the existence of a relationship between pelvic organ prolapse (POP) and recurrent urinary tract infection (UTI).

Materials and methods: The hospital database was searched for women diagnosed with pelvic floor disorders and all medical records were reviewed for recurrent UTI, diagnosed by two or more positive urine cultures taken within 12 months of each other. The control group was created using one-to-one matching for age and menopausal status. The prevalence of recurrent UTI in these patients were compared.

Results: The mean age of the 210 participants was $54.64 \pm 5.15$ years. We found no association between POP and recurrent UTI. In the prolapse group, 22 women $(21 \%)$ had recurrent UTI compared with 19 women $(18 \%)$ in the control group $(P=0.316)$. Post-void residual (PVR) volumes $>50 \mathrm{~mL}$ were associated with increased prevalence of recurrent UTI.

Conclusion: POP is not a risk factor for recurrent UTI, but women with POP are more likely to have high PVR volumes. High PVR volumes increase the risk of recurrent UTI. Clinical examination and ultrasound assessment of PVR should be performed in all women presenting with prolapse and UTI. Elevated PVR is the most significant risk factor, linking POP with recurrent UTI.

Keywords: recurrent urinary tract infection, pelvic organ prolapse, post-void residual

\section{Introduction}

The definition of urinary tract infection (UTI) encompasses a broad range of clinical entities that have in common a positive urine culture. UTI is traditionally classified into two types: uncomplicated or complicated. Uncomplicated UTI occurs in a normal urinary tract without any coexisting pathology. Complicated UTI occurs with a condition, such as functional or structural abnormalities of the urinary tract, and may not resolve rapidly with conventional antibiotics. Nitrites and leukocyte esterase tests using dipsticks have a sensitivity of $90 \%$ and a specificity of $65 \%$ for diagnosing UTI in the general population. ${ }^{1,2}$ However, the gold standard is the detection of the pathogen by urine culture. Significant bacteriuria is defined by counts of $\geq 105 \mathrm{cfu} / \mathrm{mL}$, collected from the mid-stream sample of women's urine. . $^{3,4}$

Approximately $25 \%$ of women with a history of isolated UTI have recurrent UTI, diagnosed by two or more positive urine cultures taken within 12 months of each other. ${ }^{5,6}$ In the previous literature, significant risks for an increased prevalence of recurrent UTI were found to be nulliparity and a post-void residual (PVR) volume of $>30 \mathrm{~mL} .^{7}$ Voiding dysfunction (high PVR and low flow rate) is commonly seen with pelvic organ prolapse (POP). However, interestingly, no specific
Correspondence: Emrah Töz Department of Obstetrics and Gynecology, Tepecik Training and Research Hospital, Izmir, Turkey Tel +905052595629

Fax +902322617351

Email emrahtoz79@gmail.com 
association with UTI and prolapse was seen in previous studies. ${ }^{7,8}$ Despite the link between voiding dysfunction and recurrent UTI, they found an inverse relationship between prolapse and recurrent UTI. They hypothesized that the effect of pregnancy and childbirth on relaxing and stretching the birth canal may help in preventing UTI in women with POP. ${ }^{7,8}$

This study aimed to investigate the existence of a relationship between POP and recurrent UTI. Therefore, women with and without POP were included. The prevalence of recurrent UTI in these patients was compared.

\section{Materials and methods}

This study was performed between July 2012 and July 2013 in the Department of Obstetrics and Gynecology at Tepecik Training and Research Hospital, located in Izmir, Turkey. The study was approved by the hospital's institutional review board. One hundred and five patients who were admitted to our clinic and diagnosed with at least one of the following stage 2-4 prolapse types were included: 1) descensus uteri, 2) cystocele or cystorectocele, and 3) patients with or without symptomatic urinary incontinence. The grade of urogenital prolapse was classified according to the POP quantification system (POP-Q) ${ }^{9}$ by an experienced gynecologist.

The control group (105 patients) was selected, using one-to-one matching for age and menopausal status, from patients admitted to our clinic for other benign gynecological indications such as myoma uteri, endometrial hyperplasia, or adnexal masses without evidence of POP. Exclusion criteria were stage $0-1$ prolapse, no recorded urine culture, diagnosis of interstitial cystitis, use of hormone replacement therapy, immunosuppression, urinary catheter use, ureteral stent, urinary tract abnormality or obstruction, neurogenic bladder, or multiple sclerosis. Patients with insufficient data were also excluded. Demographic characteristics including age, parity, mode of delivery, smoking and menopausal status, body mass index and presence/absence of hypertension and diabetes were recorded. PVR volume measurements were performed using transvaginal sonography (TVS) within 10 minutes after voiding. Ultrasound measurements were carried out using a SonoAce X4 sonography machine (Samsung Medison, Seoul, South Korea) by experienced gynecologist. Transvaginal route was used since it provides a better visualization of pelvic structures to define any co-existing pathology that may be present. However, if there was a large PVR volume which exceeded the accuracy of the TVS, transabdominal assessment was used instead of TVS. Bladder volumes were determined using the Haylen formula: ${ }^{10}$

$$
\text { Volume in } \mathrm{mL}=\text { Height } \times \text { Depth } \times 5.9-14.6
$$

After patient selection and PVR measurements, the medical records of both groups were reviewed retrospectively for recurrent UTI. Recurrent UTI was diagnosed by two or more positive urine cultures taken within an immediate 12-month period prior to the patient recruitment. Patients who presented with irritative voiding symptoms such as burning, dysuria, nocturia, and urgency underwent urine culture testing. Both groups were compared in terms of the presence of recurrent UTI.

Chi-squared tests were used to analyze qualitative variances. Descriptive statistics were used to constitute demographic characteristics. A threshold of $P<0.05$ was considered to indicate statistical significance. Data were analyzed using Statistical Package for the Social Sciences Version 18.0 (SPSS Inc., Chicago, IL, USA).

\section{Results}

The mean age of the 210 participants was $54.64 \pm 5.15$ years. Demographic and clinical characteristics of the two groups are summarized in Table 1. Age, body mass index, parity, mode of delivery, menopausal status, smoking status, and presence/absence of hypertension and diabetes did not differ significantly between the two groups.

We found no association between POP and recurrent UTI. In the prolapse group, 22 women (21\%) had recurrent UTI compared with 19 women (18\%) in the control group $(P=0.316)$.

Table I Clinical and demographic characteristics of the study and control groups

\begin{tabular}{llll}
\hline Characteristics & $\begin{array}{l}\text { Study group } \\
(\mathbf{n}=105)\end{array}$ & $\begin{array}{l}\text { Control group } \\
(\mathbf{n}=105)\end{array}$ & $P$-value \\
\hline Age (years) & $53.70 \pm 4.64(49-6 \mathrm{I})$ & $55.58 \pm 5.66(49-6 \mathrm{I})$ & 0.222 \\
$\begin{array}{l}\text { Body mass } \\
\text { index }\left(\mathrm{kg} / \mathrm{m}^{2}\right)\end{array}$ & $28.34 \pm 3.4 \mathrm{I}(23-35)$ & $28.96 \pm 3.18(24-34)$ & 0.479 \\
Parity & $3.56 \pm 1.28(2-6)$ & $3.36 \pm \mathrm{I} .32(\mathrm{I}-7)$ & 0.142 \\
Vaginal birth & $95(90 \%)$ & $97(92 \%)$ & 0.174 \\
Cesarean section & $10(10 \%)$ & $8(8 \%)$ & 0.242 \\
Postmenopausal & $57(54 \%)$ & $55(52 \%)$ & 0.384 \\
status & & & \\
Smoking status & $4(4 \%)$ & $6(6 \%)$ & 0.070 \\
Hypertension & $29(28 \%)$ & $26(25 \%)$ & $0.46 \mathrm{I}$ \\
Diabetes mellitus & $7(7 \%)$ & $9(8 \%)$ & 0.059 \\
Recurrent UTI & $22(21 \%)$ & $19(18 \%)$ & 0.316 \\
\hline
\end{tabular}

Note: Data are shown as mean \pm standard deviation (range), or $n(\%)$. Abbreviation: UTI, urinary tract infection. 
PVR volumes were measured immediately after micturition. The overall frequency of the PVR volumes is shown in Table 2.

Using TVS, 86 patients $(82 \%)$ had a PVR volume of $<50 \mathrm{~mL}$, and 19 patients (18\%) had a PVR volume of $>50 \mathrm{~mL}$ in the study group. PVR volumes of $>50 \mathrm{~mL}$ were associated with increased prevalence of recurrent UTI. Sixteen of the 19 women with $50 \mathrm{~mL}$ or higher PVR volumes had been diagnosed with recurrent UTI. Only six women with recurrent UTI had $50 \mathrm{~mL}$ or less PVR volume in the study group. The difference was statistically significant ( $P=0.032$ ) (Table 3$)$.

In the control group, 98 patients $(93 \%)$ had a PVR volume of $<50 \mathrm{~mL}$, and seven patients (7\%) had a PVR volume of $>50 \mathrm{~mL}$. No relationship was found between PVR volume and recurrent UTI prevelance in the control group.

\section{Discussion}

This study found that patients with POP are not more likely to be diagnosed with recurrent UTI than those without prolapse. The prevalence of recurrent UTI in the study group (21\%) was similar with the prevalence in the control group (19\%). However, POP indirectly affect UTI prevalance by high PVR volumes due to distortion of the lower urinary tract in POP patients.

A previous study showed that significant risk factors for an increased prevalence of recurrent UTI in women were nulliparity and a PVR volume of $>30 \mathrm{~mL} .{ }^{7}$ In our study, parity of women did not differ significantly between the two groups. We also found that women with a PVR volume $>50 \mathrm{~mL}$ were more likely to be diagnosed with recurrent UTI.

Because of distortion of the lower urinary tract, POP may cause urethral obstruction, voiding difficulties, reduced maximum urine flow rates, and elevated PVR volumes. Prolonged elevated PVR volumes may increase the risk of infection and detrusor overactivity. ${ }^{11,12}$ We also found that in the POP group, PVR volumes were higher than in the control group. In this study, we used the cut-off level of $50 \mathrm{~mL}$ for PVR volume according to American Urological Association guidelines. ${ }^{13}$

Table 2 The prevalence of post-void residual volumes

\begin{tabular}{lll}
\hline $\begin{array}{l}\text { Post-void residual } \\
\text { volumes, } \mathbf{~} \mathbf{L}\end{array}$ & $\begin{array}{l}\text { Study group } \\
(\mathbf{n}=1 \mathbf{0 5})\end{array}$ & $\begin{array}{l}\text { Control group } \\
(\mathrm{n}=105)\end{array}$ \\
\hline $0-50$ & $82 \%(86)$ & $93 \%(98)$ \\
$50-100$ & $11 \%(11)$ & $6 \%(6)$ \\
$\geq 100$ & $7 \%(8)$ & $1 \%(1)$ \\
\hline
\end{tabular}

Table 3 Recurrent UTI and PVR volumes in patients with POP

\begin{tabular}{|c|c|c|c|}
\hline $\begin{array}{l}\text { PVR volume, } \\
\mathrm{mL}\end{array}$ & $\begin{array}{l}\text { Recurrent } \\
\text { UTI }\end{array}$ & $\begin{array}{l}\text { No recurrent } \\
\text { UTI }\end{array}$ & $P$-value \\
\hline $\mathrm{PVR}<50$ & $6(6 \%)$ & 80 (76\%) & 0.032 \\
\hline$P V R \geq 50$ & $16(15 \%)$ & $3(3 \%)$ & \\
\hline
\end{tabular}

Abbreviations: UTI, urinary tract infection; PVR, post-void residual; POP, pelvic organ prolapse.

A PVR volume can be measured either with ultrasound or directly with a catheter. In previous studies, ultrasonographic residual urine volume measurements showed a high correlation with the catheterized volume. ${ }^{14,15}$ Catheterization is an invasive procedure and has a slight risk of causing infection or injury to the urethra. To avoid these risks, we chose to perform ultrasonographic residual urine volume measurements, instead of catheterization.

Strengths of our analysis include a large sample size and a comparable number of women both with and without prolapse. In addition, a long follow-up period for recurrent UTI enhanced the validity of the study.

\section{Conclusion}

POP is not a risk factor for recurrent UTI, but women with POP are more likely to have high PVR volumes. High PVR volumes increase the risk of recurrent UTI. Therefore, clinical examination and ultrasound assessment of PVR should be performed in all women presenting with prolapse and UTI. Elevated PVR is the most significant risk factor linking POP with recurrent UTI.

\section{Disclosure}

The authors report no conflicts of interest in this work.

\section{References}

1. Simerville JA, Maxted WC, Pahira JJ. Urinalysis: a comprehensive review. Am Fam Physician. 2005;71(6):1153-1162.

2. Car J. Urinary tract infections in women: diagnosis and management in primary care. BMJ. 2006;332(7533):94-97.

3. Foster RT. Uncomplicated urinary tract infections in women. Obstet Gynecol Clin North Am. 2008;35(2):235-248.

4. American College of Obstetricians and Gynecologists. ACOG Practice Bulletin No. 91: Treatment of urinary tract infections in nonpregnant women. Obstet Gynecol. 2008;11(3):785-794.

5. Gopal M, Northington G, Arya L. Clinical symptoms predictive of recurrent urinary tract infection. Am J Obstet Gynecol. 2007;197(1): 74-e1.

6. Hamid R, Losco G. Pelvic organ prolapse-associated cystitis. Curr Bladder Dysfunct Rep. 2014;9:175-180.

7. Haylen B, Lee J, Husselbee S, Law M, Zhou J. Recurrent urinary tract infections in women with symptoms of pelvic floor dysfunction. Int Urogynecol J Pelvic Floor Dysfunct. 2009;20(7):837-842.

8. Haylen BT, Krishnan S, Schulz S, et al. Has the true incidence of voiding difficulty in women been underestimated? Int Urogynecol J Pelvic Floor Dysfunct. 2007;18(1):53-56. 
9. Bump RC, Mattiasson A, Bø K, et al. The standardization of terminology of female pelvic organ prolapse and pelvic floor dysfunction. Am J Obstet Gynecol. 1996;175(1):10-17.

10. Haylen BT. Verification of the accuracy and range of transvaginal ultrasound in measuring bladder volumes in women. Br J Urol. 1989;64(4): 350-352.

11. Ramanzi LJ, Chaikin DC, Blavias JG. The effect of genital prolapse on voiding. J Urol. 1999;161(2):581-586.

12. Liang CC, Chang YL, Chang SD, Lo TS, Soong YK. Pessary test to predict postoperative urinary incontinence in women undergoing hysterectomy for prolapse. Obstet Gynecol. 2004;104(4):795-800.
13. American Urological Association. Guideline for the Surgical Management of Female Stress Urinary Incontinence: 2009 Update. American Urological Association; 2009 [updated 2012]. Available from: http://www.auanet.org/common/pdf/education/clinical-guidance/ Incontinence.pdf. Accessed July 20, 2014.

14. Choe JH, Lee JY, Lee KS. Accuracy and precision of a new portable ultrasound scanner, the BME-150A, in residual urine volume measurement: a comparison with the BladderScan BVI 3000. Int Urogynecol J Pelvic Floor Dysfunct. 2007;18(6):641-644.

15. Haylen BT, Lee J. The accuracy of post-void residual measurement in women. Int Urogynecol J Pelvic Floor Dysfunct. 2008;19(5): 603-606.

Research and Reports in Urology

\section{Publish your work in this journal}

Research and Reports in Urology is an international, peer-reviewed, open access journal publishing original research, reports, editorials, reviews and commentaries on all aspects of adult and pediatric urology in the clinic and laboratory including the following topics: Pathology, pathophysiology of urological disease; Investigation and treatment of

\section{Dovepress}

urological disease; Pharmacology of drugs used for the treatment of urological disease. The manuscript management system is completely online and includes a very quick and fair peer-review system, which is all easy to use. Visit http://www.dovepress.com/testimonials.php to read real quotes from published authors.

Submit your manuscript here: http://www.dovepress.com/research-and-reports-in-urology-journal 